\title{
Total Gut Decontamination
}

National Cancer Institute

\section{Source}

National Cancer Institute. Total Gut Decontamination. NCI Thesaurus. Code C157715.

A process that uses combinations of antibiotics to remove or reduce the gut

microbiome. 